\title{
Article \\ Enhancing Competitive Capabilities of Healthcare SCM through the Blockchain: Big Data Business Model's Viewpoint
}

\author{
Dae Hyun Jung ${ }^{1}$ \\ 1 School of Business, Pusan National University, Pusan 46241, Korea; jdh@pusan.ac.kr
}

\begin{abstract}
This study emphasizes the necessity of introducing a blockchain-based joint logistics system to strengthen the competency of medical supply chain management (SCM) and tries to develop a healthcare supply chain management (HSCM) competency measurement item through an analytic hierarchy process. The variables needed for using blockchain-based joint logistics are the performance expectations, effort expectations, promotion conditions, and social impact of the UTAUT model, and the HSCM competency results in increased reliability and transparency, enhanced SCM, and enhanced scalability. Word cloud results, analyzing the most important considerations to realize work efficiency among medical industry-related agencies, mentioned numerous words, including sudden situations, delivery, technology trust, information sharing, effectiveness, urgency, etc. This might imply the need to establish a system that can respond immediately to emergency situations during holidays. It could also suggest the importance of real-time information sharing to increase the efficiency of inventory management. Therefore, there is a need of a business model that can increase the visibility of real-time medical SCM through big data analysis. By analyzing the importance of securing reliability based on the blockchain technology in the establishment of a supply chain network for HSCM competency, we reveal that joint logistics can be achieved and synergistic effects can be created by implementing the integrated database to secure HSCM competency. Strengthening partnerships, such as joint logistics, will eventually lead to HSCM competency. In particular, HSCM should seek ways to upgrade its competitive capabilities through big data analysis based on the establishment of a joint logistics system.
\end{abstract}

Keywords: blockchain; healthcare supply chain management; logistics cooperation; big data

\section{Introduction}

Supply chain management (SCM), which connects the entire logistics pipeline with an integrated solution from raw material suppliers to product production, distribution processes, and end-users, is applied in various fields. This study focuses on the integration of supply chain management in the medical industry. Since all costs associated with the supply chain in the health care sector are rising rapidly, alternatives that can reduce these costs are needed. Naturally, healthcare-related companies are in demand of attention to reduce supply chain management and maintenance costs [1].

Implementing a healthcare supply chain management (HSCM) that can properly regulate and control uncertainties and variables arising from highly complex medical health market conditions will further enhance the efficiency of health services and help prepare measures to protect consumers, including patients, and their rights and interests. Therefore, this study recognizes the importance of supplier chain management throughout the relevant agencies in the medical industry and emphasizes the need for active adoption. However, for the successful introduction of supplier chain management in the medical sector, it is essential to establish a system where various stakeholders, including medical device manufacturers, distributors, customer departments, and logistics service providers, can share data. In particular, SCM in the healthcare sector has emerged as an unexpected challenge due to the significant and complex differences between countries, regions, and healthcare- 
related agencies, especially in the production and distribution stages, due to the large cost-increasing factors for inventory burdens. In addition, the medical sector is difficult to access, not only because it is directly related to human health, but also because the interests of doctors, patients, and the government are complicated in making purchasing decisions. Therefore, the purpose of this study is to identify the importance of HSCM and enhance the efficiency of supply chain management to derive implications and contribute to the development of HSCM.

The reason why the blockchain technology has recently emerged as a subject of social interest is the secure reliability that it provides. This technology is receiving considerable attention as interest is rising from many fields, including the medical industry. The blockchain provides a secure distributed database that can operate without centralization, using a distributed P2P network to continuously encrypt a list of sorted records, called blocks, that make up an expanded digital distributed ledger, increasing the validity of each transaction by automatically validating them on the network itself. Blockchain is also drawing attention as a platform to improve the reliability and transparency of medical data through various utilization cases, ranging from maintaining the right to use electronic health records (EHRs) to streamlining the claim processing.

The interest and drive of the blockchain have now expanded to medical information technology. Realizing the potential validity and importance of the technology in healthcare, the National Health Information Technology Coordination Office in the United States laid out an ideal challenge in 2016 to require a white paper on the potential use of the blockchain in the healthcare field. In response, several medical applications have been proposed for blockchain. While storing the entire health record within the blockchain can be regarded as a utilization case for healthcare, some potential barriers for implementation include most short-term proposals, including technical barriers related to privacy, compliance with regulatory requirements, and data storage and distribution focus on data validation, auditing, and certification.

If the vast amount of big data secured through the blockchain technology in the medical industry can be analyzed, a new concept of the business model will be implemented. Companies will maintain their businesses in the continuity of decision-making. Effective decision-making can be achieved when beneficial information is provided through optimization measures based on predictions and simulations rather than human experience and intuition. If the fundamental reason for a company's existence is to maximize profits through customer value creation, the direction of utilizing big data should focus on providing meaningful information to attract customers. The focus should be on finding ways to read and predict customers' desires through the data and find new business models based on associations between medical data items. Measures to reduce logistics costs include expanding facilities by increasing investment in social overhead capital, building and securing those logistics facilities, and introducing new logistics management techniques that companies must perform on their own. Among them, the best way to reduce logistics costs, in which companies are the main participants, is to introduce logistics cooperation. Logistics projects that have limitations at individual level will require companies to form a joint organization seeking corporate profits.

Therefore, measures that rationalize logistics need to be taken to secure big data through the reliability of the blockchain technology, as well as to expand the overall social overhead facilities in the medical industry. In the case of social overhead facilities, there is a limit to individual companies' performance, which allows them to introduce and utilize logistics cooperation with management techniques that firms can perform independently.

This study seeks to develop the competitive capacity variables of the medical institution SCM and approach the introduction plan of logistics cooperation from the perspective of big data utilization by analyzing the needs of the medical institution based on the blockchain technology.

Based on the background of the above research and problem posing, this study seeks to empirically analyze the following research objectives:

First, derive medical SCM competitive competency variables with AHP analysis.

Second, we identify the causal relationship between the intention to introduce and utilize blockchain and medical SCM.

Third, we examine the relevance of UTAUT variables regarding logistics cooperation. Fourth, we emphasize the need for logistics cooperation from the perspective of big data business models. 


\section{Theoretical Background}

\subsection{Design and Empirical Analysis of AHP Models}

Currently, it is difficult to select variables due to a lack of theoretical discussion on HSCM competency. Therefore, it is necessary to derive the key performance indicator (KPI) required for HSCM's connection to the blockchain for MIS, blockchain, and medical professionals, based on the order of priority. To this end, the analytic hierarchy process (AHP) was applied. The AHP is an analysis tool that deals with multi-criteria decision making, reflecting the views of many decisionmakers, before taking advantage of the strength to easily handle not only quantitative, but also qualitative information reflecting long experience and intuition that must be considered [2].

Based on prior research reviews and interviews with practitioners in the medical industry, big data, and blockchain experts, this study conducted measurements using a 9-point scale for a total of 12 determinants. In a preliminary investigation on the order of priority for medical SCM advancement, it was found that increased reliability and transparency, enhanced SCM, and enhanced scalability were recognized as important factors. These results prove that increasing the level of trust and collaboration through IT infrastructure needed for the blockchain-based joint logistics is the key to overcoming the difficulties of medical SCM.

It also shows that enhanced scalability through the expansion of legal systems from a long-term perspective is another factor in strengthening HSCM capabilities. The above three factors were placed in the higher criteria. In addition, lower criteria for enhancing reliability and transparency, guarantee of uniqueness, signing and certification, prevention of redundancy, and securing traceability were derived. Sub-basics of strengthening scalability were derived from the expansion of the legal system, improvement of composing performance, support for network optimization, and establishment of an integrated $\mathrm{dB}$ network.

Based on these preliminary investigation results, the hierarchical structure of the blockchainbased medical SCM enhancement priority was set up as a three-step structural model, as shown in Figure 1, with the extracted and measurement factors at the center.

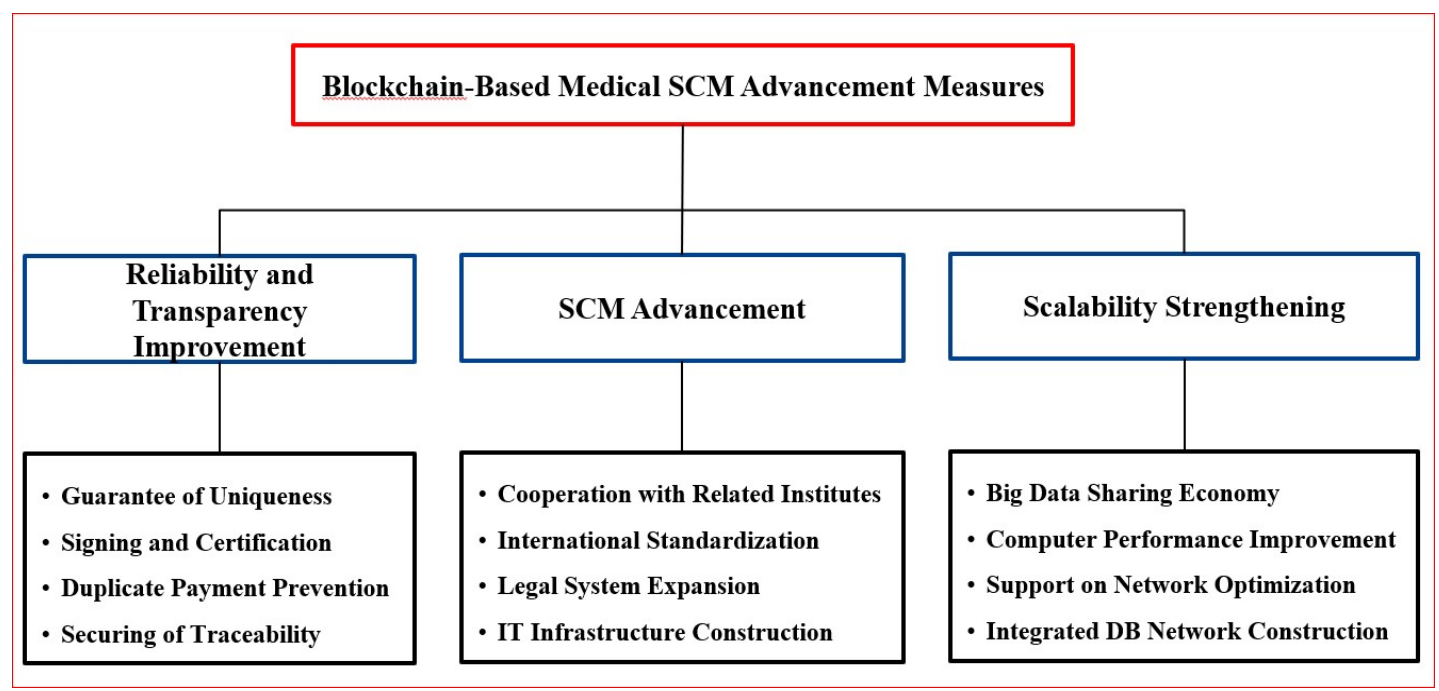

Figure 1. AHP Research Model

This study conducted a survey with experts from Busan and Gyeongnam of Korea and using a total of 12 questionnaires for the final analysis. The applicational AHP techniques recommend having 10 to 15 individuals with working knowledge and professional experience [3]. To review the reliability of the survey data, this study utilized the Consistency Ratio (CR) method for measuring the consistency of respondents in a double-contrast bridge. In general, double-contrast bridges can be reasonably assessed when the CR is less than 0.1 [4]. In this study, the CR is $0.04-0.08$, which 
indicates that reliability has been secured. Analysis of the questionnaire on the first stage evaluation items showed preference to improve reliability and transparency $(0.644)$, upgrading SCM $(0.253)$, and strengthening scalability $(0.103)$, indicating that experts consider securing reliability that reflects the characteristics of the blockchain to be the most important of the primary factors. In addition, the assessment of sub-categories, shown in Table 2, demonstrated that the single-state guarantee was the most important factor in enhancing reliability and transparency. It was analyzed that the most important factors for upgrading SCM are collaboration with related agencies and expansion of legal systems.

Table 1. Results of Pairwise Comparison in Level 1

\begin{tabular}{cccc}
\hline \multirow{2}{*}{ Type } & \multicolumn{3}{c}{ Valuation Criteria } \\
\cline { 2 - 4 } & Reliability and Transparency Improvement & SCM Advancement & Scalability Strengthening \\
\hline Importance & 0.644 & 0.253 & 0.103 \\
Rank & 1 & 2 & 3 \\
C.R. & \multicolumn{3}{c}{0.08} \\
\hline
\end{tabular}

Table 2. Results of AHP on Subfactor

\begin{tabular}{|c|c|c|c|c|c|c|c|c|c|}
\hline \multirow{3}{*}{ Representative } & \multirow{3}{*}{ Detail Element } & \multicolumn{2}{|c|}{ Itemized } & \multicolumn{6}{|c|}{ Relevance of Evaluation Criteria } \\
\hline & & \multirow{2}{*}{ Importance } & \multirow{2}{*}{ Rank } & \multicolumn{2}{|c|}{ Effectiveness } & \multicolumn{2}{|c|}{ Technology Securing } & \multicolumn{2}{|c|}{ Urgency } \\
\hline & & & & Average & Rank & Average & Rank & Average & Rank \\
\hline \multirow{4}{*}{$\begin{array}{c}\text { Enhancing } \\
\text { Reliability and } \\
\text { Transparency } \\
\text { (C.R. = 0.07) }\end{array}$} & $\begin{array}{c}\text { Guarantee of } \\
\text { Uniqueness }\end{array}$ & 0.464 & 1 & 4.50 & 1 & 4.58 & 1 & 4.33 & 2 \\
\hline & $\begin{array}{l}\text { Signing and } \\
\text { Certification }\end{array}$ & 0.336 & 2 & 4.08 & 5 & 4.08 & 5 & 4.08 & 6 \\
\hline & $\begin{array}{c}\text { Duplicate } \\
\text { Payment } \\
\text { Prevention }\end{array}$ & 0.137 & 3 & 3.83 & 8 & 3.66 & 9 & 3.58 & 10 \\
\hline & $\begin{array}{l}\text { Securing of } \\
\text { Traceability }\end{array}$ & 0.062 & 4 & 3.75 & 9 & 4.33 & 4 & 3.41 & 12 \\
\hline \multirow{4}{*}{$\begin{array}{c}\text { Advancing SCM } \\
\qquad(\text { C.R. }=0.04)\end{array}$} & $\begin{array}{c}\text { Cooperation } \\
\text { with Related } \\
\text { Institute } \\
\end{array}$ & 0.428 & 1 & 3.91 & 7 & 3.25 & 11 & 3.83 & 9 \\
\hline & $\begin{array}{c}\text { International } \\
\text { Standardization }\end{array}$ & 0.226 & 3 & 3.58 & 10 & 3.58 & 10 & 3.50 & 11 \\
\hline & $\begin{array}{c}\text { Bigdata } \\
\text { Information } \\
\text { Sharing }\end{array}$ & 0.254 & 2 & 4.08 & 5 & 4.41 & 3 & 4.25 & 4 \\
\hline & $\begin{array}{c}\text { IT } \\
\text { Infrastructure } \\
\text { Construction }\end{array}$ & 0.092 & 4 & 4.25 & 3 & 4.50 & 2 & 4.58 & 1 \\
\hline \multirow{4}{*}{$\begin{array}{c}\text { Strengthening } \\
\text { Scalability } \\
(\text { C.R. }=0.06)\end{array}$} & $\begin{array}{c}\text { Securing of } \\
\text { Legal System }\end{array}$ & 0.477 & 1 & 4.16 & 4 & 2.91 & 12 & 4.16 & 5 \\
\hline & $\begin{array}{c}\text { Improvement } \\
\text { on Computing } \\
\text { Performance } \\
\end{array}$ & 0.224 & 2 & 3.50 & 12 & 3.83 & 8 & 4.00 & 7 \\
\hline & $\begin{array}{c}\text { Support on } \\
\text { Network } \\
\text { Optimization }\end{array}$ & 0.143 & 4 & 3.58 & 10 & 4.00 & 6 & 3.917 & 8 \\
\hline & $\begin{array}{c}\text { Integrated DB } \\
\text { Network } \\
\text { Construction } \\
\end{array}$ & 0.155 & 3 & 4.33 & 2 & 3.91 & 7 & 4.33 & 2 \\
\hline
\end{tabular}

In addition, the results of compiling the relative importance of the decision items to derive the overall ranking of the detailed indicators are: From the perspective of effectiveness of final ranking, (1) uniqueness guarantee (2) integrated DB network establishment (3) IT infrastructure establishment order was high. In terms of technology security, it was ranked high in order of (1) uniqueness guarantee (2) IT infrastructure establishment, (3) sharing big data information. In terms 
of urgency, (1) IT infrastructure establishment (2) uniqueness guarantee and integrated DB network construction were high on the same average. Following the AHP analysis, both CR and lower criteria were surveyed, consisting of structural equation model measurement items, including improved reliability and transparency, enhanced SCM, and enhanced scalability as HSCM competency measurement items.

\subsection{Relationship between Logistics Cooperation and HSCM}

There have been continuous efforts to enhance SCM performance between companies. This is why the need and importance of managing SCM efficiently are emphasized. However, there are only a few studies identifying inefficient waste factors that may arise from the absence of a central logistics cooperation by medical institutions. The key point in supplier chain management is the visualization of the whole process in one system. By doing so, companies participating in the supply chain can operate efficiently by eliminating redundancy and inefficiency even among partner companies [5]. Therefore, the integration of big data is imperative.

Supply chain management focuses on the importance of supply chain efficiency. However, to understand the significance of the long-term interaction between logistics cooperation and HSCM [6], it is necessary to understand the competency of HSCM. Therefore, this study also serves as a measurement question by obtaining HSCM competency that reflects the views of experts through the AHP model. It is based on the rationale that HSCM's competition capability can be secured by utilizing the big data generated through the realization of logistics cooperation based on the blockchain technology.

\subsection{Blockchain Features and Logistics Association}

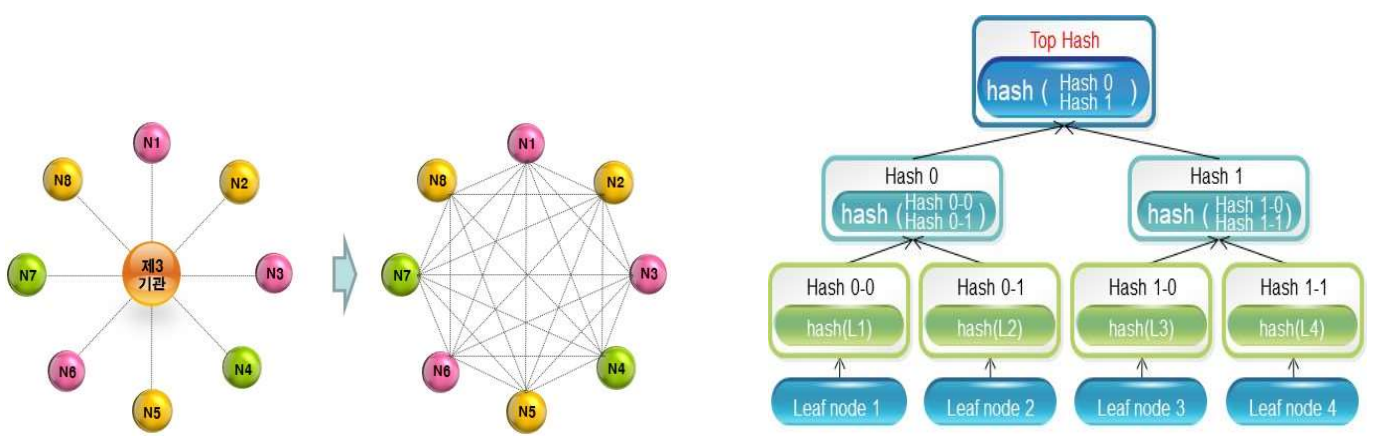

Figure 2. Diagram of basic concept of blockchain

Blockchain is a distributed ledger consisting of blocks and chains. As shown in Figure 2, a third authorized institution was previously needed, but applying the blockchain concept ensures reliability only with mutual networks. A distributed book is a repository of records of information duplicated, shared, and synchronized by consensus among participants [7]. Blocks are the key of the books in which transaction data are recorded to ensure transparency and reliability of transaction records, and these blocks have chain structures sequentially connected over time. In addition, blocks containing transaction details are chained together to create a distributed transaction book that guarantees a single reliability. At this point, all transaction books establish a chain structure where the network continues to form a blockchain that cannot be forged or altered as a "public transaction book" through distributed management.

The blockchain encryption technology utilizes Merkle Tree and public key-based digital signature techniques to verify the integrity of data [8]. A Merkle tree is a type of hash tree in which all non-leaf nodes' names consist of the hash of their children's nodes [9]. A hash is a change of a shorter length value or key that symbolizes a single string. In other words, as shown in Figure 2, leaf 
nodes point to data, such as files or specific values, and the top nodes are configured with hash values of these leaf nodes, enabling data forgery and tampering verification. Therefore, in the blockchain, the Merkle tree is composed of several hash functions that can be used to form the basis of the tree by utilizing the transaction details and information among the Leaf Node participants. Among the many hash functions that can be used to create the upper node, the Merkle tree is constructed as a SHA-256 function.

The blockchain is an encryption technology that enables safe communication between participants who do not share secret keys with each other in advance through a digital signature method based on a public key for self-certification. In this public key infrastructure, only the owner can know the open key, while the corresponding secret key is open to all participants. Thus, the open key-based digital signature method will be used in the blockchain to validate transactions. When a transaction takes place, the user signs the transaction using his secret key and sends the transaction information to all participants of the blockchain network along with his or her public key.

Table 3. Features of Blockchain

\begin{tabular}{cl}
\hline Characteristics & \multicolumn{1}{c}{ Content } \\
\hline decentralization & $\begin{array}{l}\text { Distributed public transaction books through networks between } \\
\text { individuals breaking away from centralized methods }\end{array}$ \\
\hline efficiency & $\begin{array}{l}\text { Reduces investment capital and infrastructure costs by eliminating the } \\
\text { need for trusted, authorized third parties }\end{array}$ \\
\hline scalability & $\begin{array}{l}\text { Pursues openness to enhance scalability by constructing blocks easily and } \\
\text { adopting easily through connection network }\end{array}$ \\
\hline security & $\begin{array}{l}\text { Free from malicious attacks such as hacking due to ledger open to all } \\
\text { nodes and lack of concept of central server }\end{array}$ \\
\hline transparency & $\begin{array}{l}\text { Disclose all transaction records for high transparency and reduces } \\
\text { regulatory compliance costs from easy transaction tracking }\end{array}$ \\
\hline immutableness & $\begin{array}{l}\text { Cryptographic hash of previous blocks ensures reliability as records are } \\
\text { not modified upon completion }\end{array}$ \\
\hline
\end{tabular}

All other network participants who receive this transaction information validate the transaction using the sender's public key in it. In the end, this process confirms that the transaction and information are correct and legitimately sent by the blockchain participants. Since all users participating in the blockchain network store data from the same distributed ledger, external attackers must simultaneously attempt to attack more than half of the distributed books in all networks stored by participants in order to falsify specific data, thus ensuring safety and transparency. But Proof-of-work, or consensus-induced protocol, requires an average of about 10 minutes, leading to high power consumption and low scalability due to wasted computing resources [10]. Therefore, it is not used in the blockchain released after Bitcoin. Most recently released blockchains use a vote-based consensus algorithm called Proof-of-stake, which is less secure than work-certification agreements, but solves the problem of agreement speed and power waste [11]. The characteristics of the blockchain can be summarized in Table 3, regarding decentralization, efficiency, scalability, security, transparency, and immutableness.

Following is the examination of the methods for the integration and application of blockchain in the distribution industry and SCM. Blockchain's key point is maximizing the safety of information security and transaction management. Therefore, data created in the logistics field, formed over several stages with diverse interested parties, will be utilized in various areas since the blockchain 
can share bit data created between contracting parties, shippers, and logistics companies in related organizations, to double its synergy effect.

The blockchain is the support of optimization for overall SCM, including connection between information and process, strengthening of reliability and transparency, maximizing utilization of existing legacy systems, material supply, quality management, and maintenance fields.

As the blockchain digitalizes and connects whole distribution processes from country or origin, the data can be permanently preserved as unchangeable data and utilized in various forms. In particular, the estimated amount of loss from the global damage of fake forged drugs is 200 billion dollars a year. As forged drugs are traded in about $30 \%$ of developing countries, the utilization of blockchain-based monitoring and tracking management systems for the entire process, from production to distribution and prescription, is highlighted.

\subsection{Big Data and Joint Logistics}

There is a strong need to derive critical success factors by expanding the existing research on medical institutions' joint logistics system and strengthen the medical SCM competitive capacity from the perspective of big data. In response, this study attempts to combine medical SCM competitive capacity from the perspective of practitioners in medical institutions and apply the $\mathrm{R}$ analysis method to identify operational implications. The Cyber Physical System (CPS) is one of the keywords for the 4th industrial revolution, together with AI, big data, IOT, AR, VR, and Bio. CPS represents creating new value through hyper-connection and hyper-intelligence of big data created based on IoT.

Big data is explained through $4 \mathrm{~V}$ components (volume, velocity, variety, value) and data complexity [12]. It refers to a technology that extracts value and analyzes results from a large amount of structured or non-structured data sets by a circle course of extracting, storing, analyzing, visualizing, predicting, and applying it to the existing database management tool [13].

While the concept of existing big data simply meant a large volume of data, the recent concept illustrates the collection of structured or non-structured data that is difficult to collect, store, search, analyze, and visualize in commonly used methods or tools because of being too large compared to existing data. The value of utilizing big data started from the process of creating customer-centered value and is applied to joint logistics to understand the company's situation more clearly.

The fundamental goal of big data also emphasizes the importance of sharing the value, necessary for the era of the sharing economy. Various distributed data are gathered in a certain platform based on high relevance, before being applied with the innovational multiplier effect to create new value. During an era where the value of sharing is emphasized by the concept of possession, opening and sharing of tangible and intangible assets and data owned by individuals, companies, and governments create more value. This creates a sharing society beyond the level of the sharing economy, which may realize this economy by creating a control tower where big data is shared for medical SCM as a new economy model. Therefore, the development of a business model for constructing reliable medical industry-related big data is expected to secure transparency by utilizing blockchain technologies.

In the current medical institute's business field, it is necessary to clearly suggest the fields where decisions can be made through big data analysis. With overflowing data, efficient delivery system for enhancing the synergy effect in related industries through joint logistics is needed. In order to pursue efficiency in joint logistics management through big data's connection with medical institutes, the prior task is to assess the opinions of on-site specialists on the various issues faced by the related industries in order to derive core insight.

The strategy of constructing a collaboration system through joint logistics can be accomplished by including all fields, regardless of the industry, or the presence of hostile companies, and by performing joint transportation/delivery and loading/unloading, as for example the campaign of "Business Competition \& Joint Logistics." Joint logistics will reduce their costs, provide stable logistics supply, and maintain/improve the current level of service. 
In detail, joint logistics not only contribute to reducing the costs but also enhance productivity by improving the loading rate in trucks, reducing the empty car rate, and preventing excessive transportation fee for holding unnecessary vehicles. In addition, joint logistics are greatly effective for reducing delivery time, reducing driving distance, reducing the number of personnel, making shipping work into the system, helping loading and unloading work, simplifying inspection, maintaining vehicle and facilities, preventing inspection accidents, and reducing facility investment [14].

Furthermore, they contribute to relieving traffic jams by eliminating the need for drivers' direct labor, clarifying fare systems, simplifying fare payments, and preventing overlapping cross delivery. It also provides tangible and intangible effects by reducing the daily driving in crowded city centers, reducing the risk of loss, rationalizing work handling, and reducing the harmful influence on the environment.

Constructing mutual trust between partner companies is the prior task for creating this joint logistics system in medical SCM. Therefore, to accomplish a sharing economy and analyze big data, it is necessary to construct a trust network by introducing the blockchain.

\section{Research Model and Hypotheses Establishment}

\subsection{Research Model}

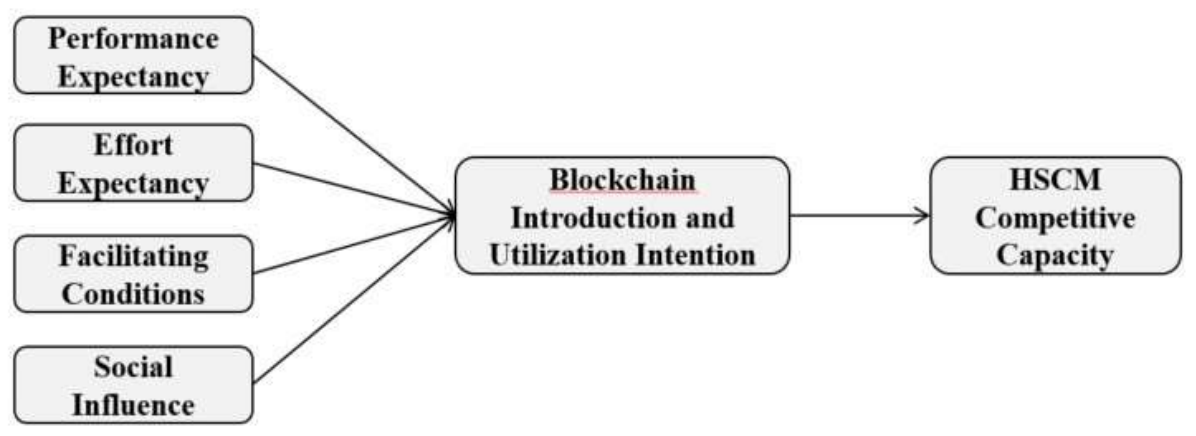

Figure 3. Research model

This study's research model has been derived, based on the theoretical background of the AHP analysis model and the UTAUT model. The research goal is to examine the need for introducing joint logistics to strengthen HSCM competitive capacity. This study conducted an empirical analysis on the effects of UTAUT's components, performance expectancy, effort expectancy, facilitating conditions, and social influence, with the intention to use and introduce the blockchain. Thus, this study tried to deduce the implications for accessing the big data sharing economy's perspective for realizing joint logistics.

\subsection{Hypothesis Establishment}

Performance expectancy refers to the degree of belief in improving work performance by using new technology, or in other words, the degree of belief in benefit from introducing and using the blockchain technology. The intention of introduction can be enhanced by expecting that utilizing the blockchain technology would help improve work efficiency by securing reliability without inconvenience.

Effort expectancy is defined as the degree of perceiving that a work can be performed easily by using new technology. In addition, effort expectancy is known to have a moderating effect based on the experience between intent and use. While such effort expectancy is an important factor in the early stage of use, its influence declines after continuous use. In the research on factors related to intention to adopt the blockchain technology conducted by Kim and Gim [15], it has been empirically analyzed that performance expectancy, social influence, and facilitating conditions influence that intention. Regarding the reasons why effort expectancy got rejected as the availability of technology 
utilization and technology introduction, the analysis shows that the desperate acceptance intention for system security strengthening and securing reliability through decentralization of the blockchain technology was weak due to lacking awareness caused by an approach different from the existing concept.

Facilitating conditions refer to the degree of an individual's belief in an organizational or structural base when using the new technology. Therefore, this study set a research model on how trust in the blockchain technology and organizations will have a moderating effect on blockchain introduction and utilization intention.

Social influence refers to the degree of belief in adopting and utilizing the new technology based on the view of other people influencing oneself [16]. It can be inferred that it is related to acceptance intention since blockchain-based joint logistics between partner companies need cooperation in the overall supply chain rather than individual companies. The acceptance intention will eventually be enhanced by securing organized support from suppliers and partner companies to construct an infrastructure for introducing the blockchain technology.

Intent to use refers to a user's intention to use the system continuously or recommend it to others. Previous studies, such as the one conducted by Davis [17], proved that this intention to use influenced the actual usage. For the UTAUT components, including performance expectancy, effort expectancy, facilitating conditions, and social influence, having a positive influence on blockchain introduction and utilization intention, this study employs the prediction of HSCM competitive capacity, blockchain introduction, and utilization intention [18]. Thus, this study set the following hypotheses regarding the relationship between blockchain introduction and utilization intention for UTAUT components:

H1: Performance expectancy will have a positive influence on the intent to introduce and utilize blockchain.

H2: Effort expectancy will have a positive influence on the intent to introduce and utilize blockchain.

H3: Facilitating conditions will have a positive influence on the intent to introduce and utilize blockchain.

H4: Social influence will have a positive influence on intent to introduce and utilize blockchain.

For HSCM's competitive capacity of achieving joint logistics by introducing blockchain, this study used the AHP analysis and derived three items, including enhancing reliability and transparency, advancing SCM, and strengthening scalability. To reach a sharing economy by introducing the blockchain technology, the top priority is to secure trust between partner companies. It is necessary to pursue advancement of medical SCM through the construction of an IT infrastructure. In addition, a big data sharing economy can be created by constructing an integrated DB network.

Accomplishing the goal of joint logistics through the supply chain [19], the ability to construct a goods delivery system within the shortest time [20], and securing flexibility to respond to unexpected situations are possible and have the capacity to adjust and revise the supply chain operating process that quickly responds to rapidly changing corporate environment changes [19]. From the perspective of SCM, introducing the blockchain technology can track goods history during the whole process, from production to moving, storage, distribution, and consumption. Realization of joint logistics by introducing the blockchain refers to the process of real-time collection and analysis of data from all processes, from production to distribution [21]. Thus, real-time information-based competitive capacity will contribute to the advancement and scalability of the medical supply chain (Will et al., 2008). In response, this study established the following hypothesis regarding the relationship between the intent to introduce and utilize blockchain and HSCM's competitive capacity.

H5: Intent to introduce and utilize blockchain will have a positive influence on HSCM's competitive capacity.

\section{Research Model and Analysis}




\subsection{Survey Composition and Features of Sample}

In this research model, all variables were applied using the Likert Scale, and the sample targeted the Busan, Gyeongnam, Seoul, and Gyeonggi-do regions of Korea. The mobile survey was conducted on pharmaceutical, manufacturing, and logistics businesses by focusing on medical institutes. Among 270 questionnaires, 261 were used after excluding those with biased distribution. For statistical analysis, SPSS 25 and Smart PLS 2.0 were used.

Table 4. Profiles of companies and respondents

\begin{tabular}{cccc}
\hline & Classification & Frequency & Percentage $(\%)$ \\
\hline \multirow{4}{*}{ Type of } & Pharmaceutical & 48 & 18.4 \\
Business & Medical Device Manufacturing & 6 & 2.3 \\
& Medical Institute & 121 & 46.3 \\
& Logistics & 73 & 28.0 \\
Gender & Service & 13 & 5.0 \\
& Male & 98 & 37.5 \\
& Female & 163 & 62.6 \\
Position & Assistant Manager & 159 & 64.8 \\
& Department Manager & 57 & 21.8 \\
& Executive & 35 & 13.4 \\
\hline \multirow{3}{*}{ No. of } & Less than 10 & 108 & 41.3 \\
Employee & $11-50$ & 49 & 18.8 \\
& $51-100$ & 19 & 7.3 \\
& $101-300$ & 53 & 20.3 \\
& 301-500 & 13 & 5.0 \\
Region & Over 500 & 19 & 7.3 \\
& Busan & 128 & 49.0 \\
& Gyeongnam & 127 & 48.7 \\
\hline & Total & 6 & 2.3 \\
\hline
\end{tabular}

For hypothesis testing, this research model adopted a partial least square (PLS) structural equation analysis because it uses the least squares method to reduce the measuring and prediction errors, enhancing verifiability for path coefficients [23].

The features of the research model are shown in Table 4 . Business type was distributed in the order of hospital and medical institutes $(46.3 \%)$, other logistics businesses, manufacturing businesses, service businesses, and medical device manufacturing businesses.

$62.6 \%$ of the respondents were female, and $37.5 \%$ male, and their positions were in the order of highest percentage, assistant manager, department manager, and executive. Regarding the number of employees at an institute, $41.3 \%$ of institutes had fewer than 10 employees, $25.1 \%$ had fewer than 100 employees, $25.3 \%$ had less than 500 employees, and $7.3 \%$ had over 500 employees. The survey region was divided across Busan (49.0\%), Gyeongnam (48.7\%), and other Seoul and Gyeonggi-do regions $(2.3 \%)$.

\subsection{Empirical Analysis and Result}

The reliability analysis of the measuring items is shown in Table 5. The values of Cronbach's $\alpha$ were over 0.660 , composition reliability $(C R)$ was over 0.734 , and average variance extracted $(A V E)$ were over 0.588 , indicating secured reliability. 
For the factor loading value of the constructs, the value was over the reference value of 0.5 . In measuring items that did not belong to each construct (Table 6), the confirmatory factor analysis results showed that all items except one value satisfied a reference value below 0.4 , and six factors were bound together with a minimum value over 0.585 . In convergent validity evaluation, factor loading for all constructs was over the reference value of 0.7 , as shown in Table 7. In addition, as the square root for the average variance extracted was higher than the correlation coefficient of other variables, it was proven that the measuring tool of this study has discriminant validity.

Table 5. Analysis on reliability and convergent validity of measuring model

\begin{tabular}{|c|c|c|c|c|c|c|}
\hline $\begin{array}{c}\text { Latent } \\
\text { Variable }\end{array}$ & $\begin{array}{c}\text { Measurement } \\
\text { Variable }\end{array}$ & $\begin{array}{c}\text { Factor } \\
\text { Loading }\end{array}$ & t-Value & AVE & C.R. & $\begin{array}{c}\text { Cronbach's } \\
\alpha\end{array}$ \\
\hline \multirow{3}{*}{$\begin{array}{l}\text { Performance } \\
\text { Expectancy }\end{array}$} & rex1 & 0.941 & $99.106^{* * *}$ & \multirow{3}{*}{0.833} & \multirow{3}{*}{0.937} & \multirow{3}{*}{0.900} \\
\hline & rex2 & 0.905 & $64.171^{* * *}$ & & & \\
\hline & rex3 & 0.892 & $69.491^{* * *}$ & & & \\
\hline \multirow{3}{*}{$\begin{array}{c}\text { Effort } \\
\text { Expectancy }\end{array}$} & eex1 & 0.914 & $5.494^{* * *}$ & \multirow{3}{*}{0.683} & \multirow{3}{*}{0.864} & \multirow{3}{*}{0.825} \\
\hline & eex2 & 0.684 & $3.434^{* * *}$ & & & \\
\hline & eex3 & 0.865 & $5.592^{* * *}$ & & & \\
\hline \multirow{3}{*}{$\begin{array}{l}\text { Facilitating } \\
\text { Conditions }\end{array}$} & acc1 & 0.940 & $133.850^{* * *}$ & \multirow{3}{*}{0.890} & \multirow{3}{*}{0.961} & \multirow{3}{*}{0.938} \\
\hline & acc2 & 0.943 & $123.789^{* * *}$ & & & \\
\hline & acc3 & 0.948 & $189.350^{* * *}$ & & & \\
\hline \multirow{3}{*}{$\begin{array}{c}\text { Social } \\
\text { Influence }\end{array}$} & soc1 & 0.873 & $29.894^{* * *}$ & \multirow{3}{*}{0.588} & \multirow{3}{*}{0.808} & \multirow{3}{*}{0.660} \\
\hline & soc2 & 0.788 & $16.908^{* * *}$ & & & \\
\hline & soc3 & 0.617 & $7.420^{* * *}$ & & & \\
\hline \multirow{4}{*}{ Intent to Use } & bin1 & 0.880 & $67.693^{* * *}$ & \multirow{4}{*}{0.804} & \multirow{4}{*}{0.943} & \multirow{4}{*}{0.919} \\
\hline & bin2 & 0.902 & $79.466^{* * *}$ & & & \\
\hline & bin3 & 0.915 & $94.288^{* * *}$ & & & \\
\hline & bin 4 & 0.889 & $62.882^{* * *}$ & & & \\
\hline \multirow{3}{*}{$\begin{array}{l}\text { Competitive } \\
\text { Capacity }\end{array}$} & abi1 & 0.837 & $51.648^{* * *}$ & \multirow{3}{*}{0.622} & \multirow{3}{*}{0.734} & \multirow{3}{*}{0.750} \\
\hline & abi2 & 0.816 & $40.482^{* * *}$ & & & \\
\hline & abi3 & 0.788 & $30.961^{* * *}$ & & & \\
\hline
\end{tabular}

${ }^{* *}: \mathrm{p}<0.05,{ }^{* * *}: \mathrm{p}<0.01$

In the convergence validity of the structural model, the communality value was over 0.5 , as shown in Table 8, satisfying the suitability to the measuring model. For $R$ Square $\left(R^{2}\right)$, an average suitability measurement for the structural model, it is classified as high (over 0.26), medium (0.13 0.26), and low (0.02 0.13), as an evaluation of path model for each endogenous variable [24]. In addition, the overall suitability of the PLS path model is the root square root of value calculated by multiplying the mean value of endogenous variable $R^{2}$ and communality. The suitability value should be at least 0.1, and it is classified as high (over 0.36), medium (0.25 0.36), and low (0.01 0.25), depending on the size. As shown in Table 8, the overall PLS path model's suitability was 0.284, representing a medium level. 
Table 6. Results of confirmatory analysis

\begin{tabular}{|c|c|c|c|c|c|c|c|}
\hline \multicolumn{2}{|c|}{ Classification } & 1 & 2 & 3 & 4 & 5 & 6 \\
\hline \multirow{4}{*}{ Intent to Use } & bin3 & 0.916 & 0.070 & 0.046 & -0.033 & 0.059 & 0.021 \\
\hline & bin1 & 0.865 & 0.118 & 0.091 & 0.031 & 0.068 & 0.039 \\
\hline & bin4 & 0.865 & 0.077 & 0.191 & 0.062 & 0.057 & 0.017 \\
\hline & bin2 & 0.859 & 0.140 & 0.136 & 0.031 & 0.052 & 0.094 \\
\hline \multirow{3}{*}{$\begin{array}{l}\text { Performance } \\
\text { Expectancy }\end{array}$} & rex1 & 0.148 & 0.860 & 0.251 & 0.054 & 0.047 & 0.042 \\
\hline & rex2 & 0.139 & 0.843 & 0.163 & -0.032 & 0.166 & 0.082 \\
\hline & rex3 & 0.161 & 0.795 & 0.215 & 0.041 & 0.041 & 0.075 \\
\hline \multirow{3}{*}{$\begin{array}{l}\text { Facilitating } \\
\text { Conditions }\end{array}$} & acc2 & 0.194 & 0.208 & 0.845 & 0.061 & 0.198 & 0.044 \\
\hline & acc3 & 0.187 & 0.280 & 0.820 & -0.005 & 0.160 & 0.061 \\
\hline & acc1 & 0.230 & 0.271 & 0.799 & 0.111 & 0.073 & 0.055 \\
\hline \multirow{3}{*}{$\begin{array}{c}\text { Effort } \\
\text { Expectancy }\end{array}$} & eex3 & 0.041 & 0.031 & 0.098 & 0.887 & 0.106 & 0.009 \\
\hline & eex2 & -0.038 & -0.052 & 0.007 & 0.850 & 0.130 & 0.009 \\
\hline & eex1 & 0.065 & 0.062 & -0.024 & 0.751 & 0.034 & 0.326 \\
\hline \multirow{3}{*}{$\begin{array}{l}\text { Competitive } \\
\text { Capacity }\end{array}$} & $\exp 2$ & 0.066 & 0.139 & 0.043 & 0.125 & 0.849 & 0.102 \\
\hline & exp1 & 0.107 & -0.010 & 0.036 & 0.220 & 0.813 & -0.015 \\
\hline & exp3 & 0.082 & 0.113 & 0.329 & -0.004 & 0.789 & 0.039 \\
\hline \multirow{3}{*}{$\begin{array}{c}\text { Social } \\
\text { Influence }\end{array}$} & soc2 & 0.088 & 0.003 & 0.063 & 0.126 & -0.006 & 0.820 \\
\hline & soc3 & 0.009 & 0.253 & -0.025 & 0.045 & 0.187 & 0.605 \\
\hline & soc1 & 0.127 & 0.163 & 0.157 & 0.498 & 0.102 & 0.585 \\
\hline
\end{tabular}

Table 7. Analysis on discriminant validity of measuring model

\begin{tabular}{|c|c|c|c|c|c|c|}
\hline & $\begin{array}{l}\text { Performance } \\
\text { Expectancy }\end{array}$ & $\begin{array}{c}\text { Effort } \\
\text { Expectancy }\end{array}$ & $\begin{array}{l}\text { Facilitating } \\
\text { Conditions }\end{array}$ & $\begin{array}{c}\text { Social } \\
\text { Influence }\end{array}$ & $\begin{array}{l}\text { Intent } \\
\text { to Use }\end{array}$ & $\begin{array}{c}\text { Competitive } \\
\text { Capacity }\end{array}$ \\
\hline $\begin{array}{c}\text { Performance } \\
\text { Expectancy }\end{array}$ & .913 & & & & & \\
\hline $\begin{array}{c}\text { Effort } \\
\text { Expectancy }\end{array}$ & .097 & .826 & & & & \\
\hline $\begin{array}{l}\text { Facilitating } \\
\text { Conditions }\end{array}$ & .558 & .157 & .943 & & & \\
\hline $\begin{array}{c}\text { Social } \\
\text { Influence }\end{array}$ & .304 & .428 & .281 & .767 & & \\
\hline Intent to Use & .316 & .076 & .380 & .194 & .897 & \\
\hline $\begin{array}{c}\text { Competitive } \\
\text { Capacity }\end{array}$ & .284 & .265 & .410 & .362 & .126 & .789 \\
\hline
\end{tabular}

* Bold Item in Diagonal Line : AVE Square Root

Table 8. Analysis on fitness of structural model

$\begin{array}{llll}\text { Constructs } & \text { R Square } & \text { Communality } & \text { Redundancy }\end{array}$




\begin{tabular}{clll}
\hline Performance Expectancy & 0.833 \\
\hline Effort Expectancy & 0.683 & \\
\hline Facilitating Conditions & 0.890 & \\
\hline Social Influence & 0.171 & 0.588 & 0.052 \\
\hline Intent to Use & 0.048 & 0.804 & 0.010 \\
\hline Competitive Capacity & & $\sqrt{0.110 \times 0.737}=0.284$ & \\
\hline Overall Model Fitness & & & \\
\hline
\end{tabular}

\subsection{Hypothesis Testing}

Hypothesis H1 ( $\beta=0.128, t=2.635)$, regarding how performance expectancy will have a positive influence on the intent to introduce and utilize the blockchain, showed statistical significance at a significance level of $\mathrm{p}<0.001$. Hypothesis $\mathrm{H} 2(\beta=0.006, \mathrm{t}=0.132)$, analyzing how effort expectancy will have a positive influence on the intent to introduce and utilize the blockchain, did not show statistical significance. Hypothesis $\mathrm{H} 3(\beta=0.285, \mathrm{t}=5.985)$ which examined how facilitating conditions will have a positive influence on the intent to introduce and utilize the blockchain showed statistical significance at a significance level of $\mathrm{p}<0.001$. Hypothesis $H 4(\beta=0.099, \mathrm{t}=2.031)$, regarding the way social influence will have a positive impact on the intent to introduce and utilize the blockchain, showed statistical significance at a significance level of $p<0.05$. Hypothesis $H 5 \quad(\beta=0.197, t=4.451)$ which focused on how the intent to use will have a positive influence on HSCM's competitive capacity showed statistical significance at a significance level of $\mathrm{p}<0.001$.

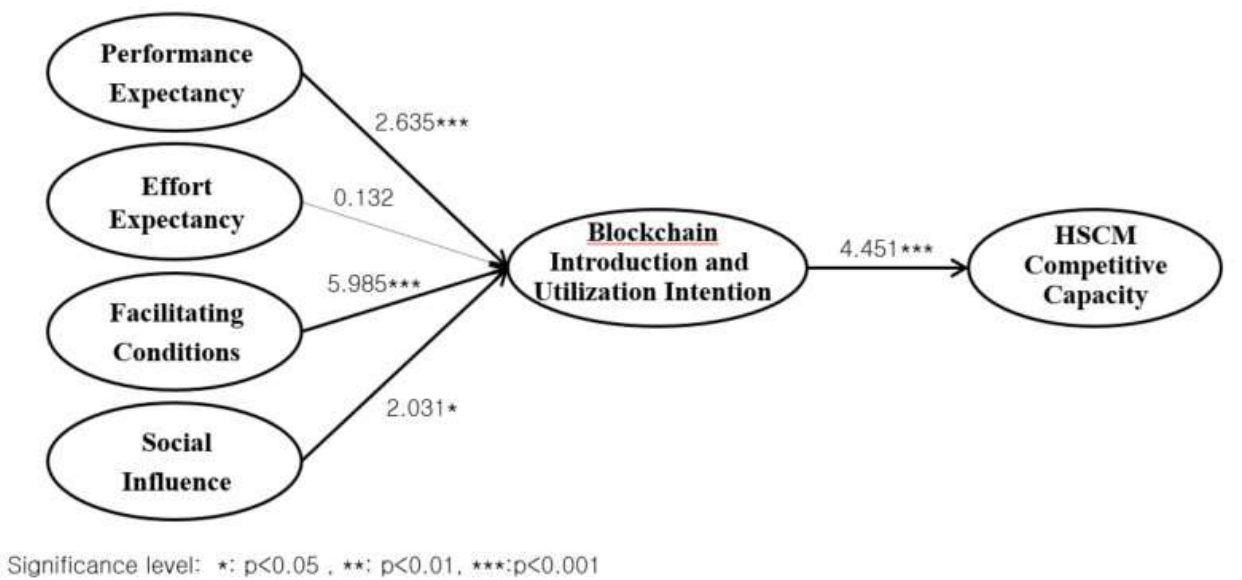

Figure 4. Hypothesis testing results

Figure 5 shows the results of the wordcloud analysis regarding the utilization of $\mathrm{R}$ to deduce major implications for achieving work efficiency between cooperative companies in medical institutes. In word cloud, words and phrases, such as unexpected situations, delivery, trust in technology, sharing, information, effectiveness, and emergency, were often mentioned. This result implies the necessity of constructing a system for immediate delivery in unexpected situations on weekends and holidays. The results also highlight the necessity of smooth communication and information sharing through a mutual-trust system. In addition, the results demonstrate the need for efficient inventory management. Therefore, the field needs to pursue a HSCM business model that 
analyzes big data mutually between related institutes, achieving real-time SCM to enhance visibility in information sharing.

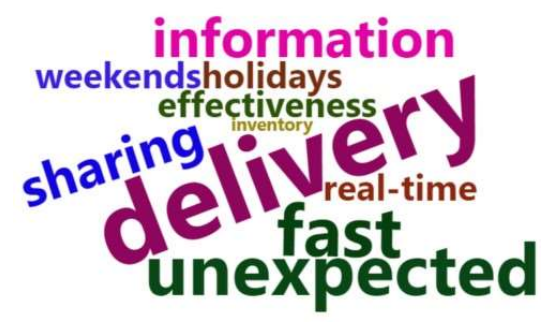

Figure 5. Wordcloud analysis results

\section{Conclusion}

To advance the medical institutes' competitive capacity, it is necessary to introduce joint logistics through big data information sharing. This study applied medical SCM competitive capacity toward the intent to introduce the blockchain technology and the need for joint logistics from the perspective of big data. There are various fields where big data can be utilized by medical institutes, such as improvement of internal business handling, better targeting of products and services provided to customers, and change of all business models for utilizing real-time information and feedback. In the medical SCM field, joint logistics is likely to be applied to reduce the investment risk by reducing the required time for each process, enhancing the rate of on-time delivery, and increasing the logistics center and vehicles in the short and long term. Therefore, this study examined the perspective of big data to analyze the close relationship between partner companies, such as to matching supply with demand between them, reducing inventory level, enhancing logistics delivery, and creating an opportunity to shorten the new product release period.

First, regarding the factors causing the progress of the blockchain-based medical SCM competitive capacity, this study selected enhancement of reliability and transparency, advancement of SCM, and strengthening of scalability. Securing reliability is the most crucial part in introducing the strengths of the blockchain between partner companies in the medial industry field. Therefore, securing a guarantee of uniqueness through the blockchain technology is most needed. Furthermore, the AHP analysis results showed that cooperation with related institutes and the expanded legal system secure the HSCM competitive capacity the most. To store and utilize sensitive personal information, such as medical data, data can be saved with the blockchain technology's encryption, and the user can realize big data information sharing through the right to access. By utilizing decentralized blockchain technology to solve reliability, security, and sharing issues, the blockchain is expected to reach the era of a sharing economy where treatment and customized care are available.

Second, in the sub-factor AHP analysis and relative importance analysis depending on effectiveness, technology securing, and urgency, the importance followed the order of guarantee of uniqueness, integrated DB network construction, and IT infrastructure construction. This represents the strong need for constructing an IT infrastructure, such as an integrated database guaranteeing uniqueness through the blockchain technology. This also implies that a synergy effect can be created by constructing an integrated database in the overall medical industry to advance HSCM's competitive capacity. This study also clarifies the prerequisite of building trust between partner companies based on the blockchain.

Third, among the UTAUT components, performance expectancy, facilitating conditions, and social influence had a significant impact on the intent to introduce and utilize the blockchain. However, effort expectancy did not influence this intent. This showed that constructing an infrastructure based on technology, such as the blockchain, will be introduced positively in terms of work efficiency and convenience. It is assumed that the importance of cooperative relationships in the overall supply chain is applied regarding blockchain-based joint logistics throughout the medical industry. Eventually, positive acceptance of the ripple effect caused by securing the blockchain 
technology will enhance the intent to accept it. However, another interpretation suggests that the awareness of the need for introducing a method that is different from the existing ones, such as effort expectancy, was relatively passive.

Fourth, the intent to introduce and utilize the blockchain had a significant influence on HSCM's competitive capacity. Expected effects, such as enhancing reliability and transparency, advancing SCM, and strengthening scalability, predict new practical benefits from achieving joint HSCM logistics. It is necessary to promote the intent to use joint logistics based on expected effects, such as enhanced flexible response to demand variation, enhanced capacity for goods improvement and change, and enhanced response to market environment changes.

Fifth, while existing HSCM-related studies lacked an examination of the connection between the blockchain and joint logistics, this study analyzed this connection under the aspect of big data, emphasizing the necessity to secure reliability as a blockchain's core success factor and expand its utilization regarding big data businesses in order to settle joint logistics. While some types of SCM competitive capacity that affected the related institute's performance and continuous connection eventually had direct and indirect influence on joint logistics, there were only a few studies that clarified such influence, and our research expected to provide a new framework. Therefore, by considering the need to introduce joint logistics as a practical measure for enhancing SCM performance in the medical industry field and strengthening the partnership, such as information sharing, it would be possible to establish a big data business model. In response to the rise of the 4th industrial revolution era, big data is strongly needed. Utilizing big data formed through joint logistics on medical SCM would allow the operation of a control center that enables strategic thinking, such as cooperation and price, enhancing the synergy effect. Constructing a big data business model is expected to enhance medical institutes' capacity.

This study's academic and practical implications are as follows: Since securing blockchain technology-based HSCM competitive capacity showed statistical significance in joint logistics, this study suggested a direction for establishing a strategy for related institutes in the medical field. This paper also suggested the need for constructing joint logistics through the introduction of the blockchain, which will be an innovation in the comprehensive application on a supply chain network composed of numerous members. Medical SCM's competitive capacity will ultimately lead to strengthened co-operative competitive capacity, such as joint logistics. This study demonstrated the importance of the intent to use the blockchain technology. The factors that reinforce joint logistics in the supply chain will be key in forming relationships with partner companies. This has been proven in numerous preceding studies, and it is important to apply the blockchain technology on the basis of strong reliability. In addition, SCM's competitive capacity should be enhanced by pursuing a strategic approach between companies regarding joint logistics system to induce the partnerships between them. In particular, it is necessary to pursue ways to utilize HSCM by analyzing big data for the construction of a joint logistics system.

The limitations of this study, and the directions for follow-up research are as follows: First, this study could not consider the characteristics of the scale of the medical institute. There may be differences in the intent to introduce the blockchain depending on the scale of the medical institute. Therefore, follow-up studies should take this limitation into consideration and carry out various analyses to deduce meaningful results. Second, it is necessary to enhance generalization by expanding the sample to the national level and collecting more data. Third, a more meaningful approach would include classifying companies into upstream/downstream cooperative companies focusing on medical institutes and expanding the scope of the research.

\section{References}

1. Park, K.O.; Chang, H.S.; Jung, D.H. How Do Power Type and Partnership Quality Affect Supply Chain Management Performance?. Sustainability, 2017, 9, 1-15.

2. Park, G.S.; Bae, B.H.; Cho, G.S. Developing the Weights of Key Performance Indicators Based on B SC Perspectives Using the AHP in RND Area. Korean Association of Business Education, 2006, 4, 1 19-137.

3. Giokas, D.I.; Pentzaropoulos, G.C. Efficiency ranking of the OECD member states in the area o 
f telecommunications: A composite AHP/DEA study. Telecommunications Policy, 2008, 32, 672-6 85 .

4. Saaty, T.L. The Analytic Hierarchy Process: Planning, Priority Setting, Resource Allocation. New York: McGraw-Hill, 1980.

5. Lummus, R.R.; Krumwied, D.W.; Vokurka, R.J. The Relationship of Logistics to Supply Chain Management: Developing a Common Industry Definition. Industrial Management and Data Systems, 2001, 101, 426-431.

6. Chen, C.A. Revisiting Organizational Age, Inertia, and Adaptability: Developing and Testing a MultiStage Model in the Nonprofit Sector. Journal of Organizational Change Management, 2014, 27, 251-272

7. Walport, M. Distributed Ledger Technology: Beyond Blockchain, UK Government Office for Science, 2016, 19.

8. Antonopoulos, A.M. Mastering Bitcoin: Unlocking Digital Cryptocurrencies, O’Reilly Media, 201 5.

9. Merkle, R.C. A Digital Signature Based on a Conventional Encryption Function. Advances in Cryptology - CRYPTO’ 87, Lecture Notes in Computer Science, 2000, 293, 369-378.

10. Nakamoto, S. Bitcoin: A Peer-to-Peer Electronic Cash System. cryptovest.co.uk, 2008.

11. Vasin, P. Blackcoin's Proof-of-Stake Protocol V2. www.blackcoin.co, 2014.

12. Gartner, The Internet of Things, Worldwide. Gartner, Archived Published, Connecticut in USA. 2013.

13. Lee, J.S.; Hong, S.C. Study on the Application Methods of Big Data at a Corporation: Cases of A and Y corporation Big Data System Projects. Journal of Internet Computing and Services, 2014, 15, 103-112.

14. Myhr, N.; Spekman, R.E. Collaborative supply chain partnerships built upon trust and electronically mediated exchange. Journal of Business \& Industrial Marketing, 2005, 20, 179-186.

15. Kim, J.S.; Gim, G.Y. A Study on Factors Affecting the Intention to Accept Blockchain Technology. Journal of Information Technology Services, 2017, 16, 1-20.

16. Lu, J.; Yao, J.E.; Yu, C.S. Personal Innovativeness: Social Influences and Adoption of Wireless Internet Services via Mobile Technology. The Journal of Strategic Information Systems, 2005, 14, 245-268.

17. Davis, F.D. Perceived Usefulness, Perceived Ease of Use, and User Acceptance of Information Technology. MIS Quarterly, 1989, 13, 319-339.

18. Venkatesh, V.; Morris, M.G.; Davis, G.B.; Davis, F.D. User Acceptance of Information Technology: Toward a Unified View. MIS Quarterly, 2003, 27, 425-478.

19. Rosenzweig, E.D.; Roth, A.V. Towards a Theory of Competitive Progression: Evidence from High-Tech Manufacturing. Production and Operations Management, 2004, 13, 354-368.

20. Ward, P.T.; Duray, R. Manufacturing Strategy in Context: Environment, Competitive Strategy and Manufacturing Strategy. Journal of Operations Management, 2000, 18, 123-138.

21. Mandal, D.; McQueen, R.J. Extending UTAUT to Explain Social Media Adoption by Microbusinesses. International Journal of Managing Information Technology, 2012, 4, 1-21.

22. Wills, M.J.; El-Gayar, O.F.; Bennett, D. Examining Healthcare Professionals' Acceptance of Elect ronic Medical Records Using UTAUT. Issues in Information Systems, 2008, 9, 396-401

23. Chin, W.W.; Newsted, P.R. Structural Equation Modeling Analysis with Small Sampling Using Partial Least Squares, In Statistical Strategies for Small Sample Research, R.H. Hoyle(Eds.), Sage, 1999, $307-$ 341.

24. Cohen, J. Statistical Power Analysis for the Behavioral Sciences (2nd ed.), Hillsdale, New Jerse y: Lawrence Erlbaum. 1988. 